\title{
NOTICIARIO
}

\section{Caracterización morfológica de almidones de los géneros Triticum y Hordeum en la Península Ibérica}

\author{
Morphological characterization of starch grains from the genera Triticum and Hordeum \\ in the Iberian Peninsula
}

\author{
Francisco Javier Aceituno Bocanegra (*) \\ José Antonio López Sáez (**)
}

\section{RESUMEN}

Los granos de almidón son cada vez más utilizados en los estudios arqueobotánicos como marcadores de la dieta, la domesticación de plantas, el uso de herramientas y la organización microespacial de los yacimientos arqueológicos, debido a que su morfología y características permiten identificar las plantas que los produjeron. En el presente trabajo se caracterizan morfométricamente los granos de almidón de cinco especies del género Triticum y tres variedades de Hordeum vulgare. Además se hace un balance de los estudios de almidones realizados en la Prehistoria de la Península Ibérica, señalando los logros, las debilidades y futuras directrices para potenciar este tipo de análisis bioarqueológico; especialmente la necesidad de contar con amplias colecciones de referencia, la aplicación de análisis estadísticos paralelos, y la realización de estudios experimentales para controlar los procesos de alteración de los almidones.

\begin{abstract}
Starch grains are increasingly used in archaeobotanical studies as markers of diet, plant domestication, tool use and site organization in archaeological research, because their morphology and features provide a means
\end{abstract}

(*) Dpto. de Antropología, Grupo Medioambiente y Sociedad, Facultad de Ciencias Sociales y Humanas, Universidad de Antioquia. Calle 67, 53-108. Bloque 9, oficina 258, Colombia. Correo e.: csfjaia@antares.udea.edu.co

(**) Grupo de Investigación Arqueobiología, Instituto de Historia, Centro de Ciencias Humanas y Sociales, CSIC. C/ Albasanz 26-28. 28037 Madrid.

Correo e.: joseantonio.lopez@cchs.csic.es

Recibido: 6-V-2011; aceptado: 6-VII-2011. to identify the plant that produced them. In this paper we characterize morphometrically the starch grains of five species of the genus Triticum and three varieties of Hordeum vulgare. In addition there is an assessment of the studies of starch grains made in the Prehistory of the Iberian Peninsula, indicating the achievements, the weaknesses and future directions to promote this type of bioarchaeological analysis; especially, there is a need to rely on wide reference collections, as well as apply statistical analyses and carry out experimental studies to control the processes of alteration of the starch grains.

Palabras clave: Almidones; Triticum; Hordeum; Recursos vegetales; Arqueobotánica; Análisis de residuos; Península Ibérica.

Key words: Starch grains; Triticum; Hordeum; Plant resources; Archaeobotany; Residue Analysis, Iberian Peninsula.

\section{INTRODUCCIÓN}

El análisis de restos de almidones ha adquirido un notable protagonismo en los estudios bioarqueológicos en las últimas décadas, gracias a que la variabilidad morfológica y la perdurabilidad de este registro fósil, en contextos arqueológicos, ha permitido abordar interesantes problemáticas. Unas se relacionan con el origen y difusión de la agricultura y el consumo de elementos vegetales, en el Neotrópico (Piperno y Pearsall 1998; Piperno et al. 2000; Piperno et al. 2004; Iriarte et al. 2004; Pearsall et al. 2004; Pagan et al. 2005; Dickau et al. 2007; Perry et 
al. 2007; Aceituno y Loaiza 2008; Piperno 2009), África (Mercader 2009), Oceanía (Loy et al. 1992; Horrocks et al. 2004; Fullagar et al. 2006; Wilson et al. 2010) y Próximo Oriente (Piperno et al. 2004; Henry y Piperno 2008). Otras se refieren al uso concreto dado a ciertos artefactos líticos y recipientes cerámicos datados tanto en el Pleistoceno como en el Holoceno (Ugent et al. 1982, 1984, 1986; Loy et al. 1992; Loy 1994; Fullagar et al. 1996; Piperno y Holst 1998; Lentfer et al. 2002; Perry 2002, 2004; Haslam 2004; Piperno et al. 2004; Barton 2005, 2007; Aranguren et al. 2007; Dickau et al. 2007; Aceituno y Loaiza 2008; Piperno y Dillehay 2008; Hardy et al. 2009; Piperno 2009; Revedin et al. 2010). Las terceras atañen a la documentación de la dieta de los grupos humanos del pasado (Piperno et al. 2000; Babot 2003; Piperno et al. 2004; Barton 2007), a la evaluación de la organización social y espacial de los yacimientos determinando las áreas de actividad (Balme y Beck 2002; Henry et al. 2004), a la reconstrucción de la vegetación del pasado y a la dinámica antrópica en un sentido diacrónico (Lenfter et al. 2002).

Los almidones constituyen la principal fuente de almacenamiento de energía en los vegetales, ya que se encuentran en grandes cantidades en semillas, raíces, tubérculos y algunas frutas. La concentración de los mismos varía según su estado de madurez (Loy 1994; Thomas y Atwell 1999; Haslam 2004; Wilson et al. 2010). Del $70 \%$ al $80 \%$ de las calorías consumidas por los seres humanos proviene del almidón, el carbohidrato más abundante en la naturaleza (Knutzon y Grove 1994; Yuryev et al. 1995; Hoover 2001; Tomlinson y Denyer 2003; Haslam 2004).

Estructuralmente, el almidón consiste en dos polisacáridos de glucosa químicamente distinguibles, la amilosa y la amilopectina. Los vegetales los sintetizan mediante la absorción de agua del suelo y de dióxido de carbono de la atmósfera durante la fotosíntesis (Loy 1994: 89), aunque en ocasiones contienen pequeñas cantidades de lípidos y minerales (Hoover 2001; Wilson et al. 2010). La relación entre ambos polímeros varía de unas especies a otras. La proporción amilopectina-amilosa en los cereales es del orden de un 3:1 o 2:1 (Zobel 1988; Haslam 2004). Las plantas producen almidones en la mayoría de sus tejidos, pero son particularmente abundantes en frutos, semillas y órganos de reserva subterráneos donde el almacenamiento energético a largo plazo es necesario (Swinkels 1985).

La morfología de los granos de almidón está determinada genéticamente y varía a nivel de familia, género o entre especies. La base es su tamaño, forma y la presencia o aparición de ciertas características ornamentales como el hilum o 'Cruz de Malta' (punto de nucleización a partir del cual se forman los granos de almidón), las lamellae (anillos internos entre las capas cristalinas y amorfas del grano de almidón), la visibilidad de las estrías, el grado de agregación, etc. (Reichert 1913; Esau 1953; Seidemann 1966; Torrence y Barton 2006). Gran parte de su forma está determinada por la acción de las enzimas que, a su vez, establece la estructura de las moléculas de amilopectina (Wilson et al. 2010). Otros factores que influyen son las condiciones ambientales, la ubicación espacial y la cantidad de gránulos de los plástidos (Hoover 2001; Tomlinson y Denyer 2003). Las especies de pocos granos tienden a las formas regulares y las de cantidades muy altas a las irregulares, angulares y con facetas de presión (Tomlinson y Denyer 2003). Los granos de almidón son observables al microscopio óptico gracias a sus propiedades cuasi-cristalinas, tales como anisotropía óptica y doble refracción (Loy 1994).

A finales de los 1990, los almidones incrementaron el tipo de evidencias arqueobotánicas susceptibles de ser analizadas en el registro arqueológico de la Península Ibérica. Estos estudios pioneros prestaron especial atención a yacimientos arqueológicos de cronología neolítica y protohistórica (Juan-Tresserras 1995, 2000a, 2000b, 2000c; Juan-Tresseras et al. 1996)(1). Los resultados derivados de estas investigaciones, inicialmente muy promisorios para profundizar en la relación entre el ser humano y las plantas, no adquirieron la relevancia que deberían haber tenido.

Ello se explica por sus deficiencias metodológicas y argumentativas que provocaron numerosas reticencias entre los bioarqueólogos peninsulares. Ninguna de las publicaciones describía, por ejemplo, el protocolo de extracción de las mues-

(1) Juan-Tresserras, J. 1997: Procesado y preparación de alimentos vegetales para consumo humano. Aportaciones del estudio de fitolitos, almidones y lípidos en yacimientos arqueológicos prehistóricos y protohistóricos. Tesis Doctoral inédita. Facultad de Prehistoria, Historia Antigua y Arqueología, Universidad de Barcelona. Barcelona. 
tras según el contexto arqueológico de procedencia, ni los detalles diagnósticos sobre los parámetros de identificación taxonómica seguidos. Tampoco se indicaba si se había utilizado una colección comparativa de referencia, ni las variables consideradas. En definitiva, la presentación de los datos se resumía en un listado de tipos morfológicos específicos sin material fotográfico de apoyo, ni información auxiliar morfométrica de contraste.

El objetivo de este trabajo es presentar las bases metodológicas para caracterizar morfológica y métricamente los granos de almidón en especies de los géneros Triticum y Hordeum y discutir algunos de los resultados de las investigaciones previas al respecto en yacimientos de la Península Ibérica. El almidón de estos dos géneros de cereales, por su importancia económica e industrial, principalmente se ha estudiado desde una perspectiva agropecuaria, centrada en su composición y alteración química bajo determinadas condiciones agroecológicas, su morfología y sus usos industriales (Tomlinson y Denyer 2003; Zhong-Min et al. 2008; Vasanthan y Hoover 2009). En cambio se han obviado rasgos, como los ornamentales, básicos a la hora de aplicar este tipo de análisis al registro arqueológico.

\section{MATERIAL Y MÉTODOS}

Se eligieron y procesaron 5 especies de trigo y 3 variedades de cebada (Tab. 1), por ser los cereales más abundantes en el registro carpológico de la Prehistoria de la Península Ibérica (Buxó 1997; Buxó et al. 1997; Zapata et al. 2004, 2005; Buxó y Piqué 2008).
La preparación de las muestras consistió en triturar las semillas seleccionadas en un mortero para disgregar los granos de almidón. El residuo fue tamizado en una malla de $5 \mathrm{~mm}$ para limpiar la muestra de otros tejidos vegetales, montándolo con glicerina en placas portaobjetos, con el fin de rotar los granos de almidón para su visualización por microscopía óptica.

En la caracterización morfológica y el registro fotográfico de los gránulos se utilizó un estereomicroscopio Nikon L-50 de luz polarizada con contraste de fase y magnificación moderada (x100). El método es el más apropiado para la identificación de almidones procedentes de contextos arqueológicos por no ser costoso y necesitar poco tiempo (Henry et al. 2009). La caracterización de los almidones se reforzó mediante un microscopio electrónico de barrido (modelo Hitachi). Esta técnica permitió su observación a mayores aumentos y en tres dimensiones corroborando algunos detalles de la composición y superficie de los mismos.

El número de granos de almidón muestreados, en los 8 taxa analizados, fue (Tab. 1): 93 en Triticum aestivum; 105 en $T$. dicoccum; 126 en T. durum; 85 en T. monococcum; 81 en T. turgidum; 83 en Hordeum vulgare subsp. distichum y 81 en su variedad nudum; 98 en Hordeum vulgare subsp. vulgare var. nudum. Estos valores son acordes con los estándares internacionales de significancia estadística, que recomiendan un número mínimo de 100 granos cuando se trata de una nueva especie y menos si se trata de especies conocidas como es el caso (Dickau com. pers.).

Los granos de almidón se caracterizaron según variables métricas y cualitativas (Seidemann 1966; Cortella y Pochettino 1994; Fullagar et al. 1996; Perry 2002, 2004; Dickau 2005; Torrence y Bar-

\begin{tabular}{|l|l|l|}
\hline \multicolumn{1}{|c|}{ Taxón } & Tipo de semilla & \multicolumn{1}{c|}{ Nombre vernáculo } \\
\hline Triticum aestivum & Desnuda & Trigo harinero \\
Triticum dicoccum & Vestida & Escanda melliza \\
Triticum durum & Desnuda & Trigo duro \\
Triticum monococcum & Vestida & Escaña \\
Triticum turgidum & Desnuda & - \\
Hordeum vulgare subsp. distichum & Vestida & Cebada de dos carreras vestida \\
Hordeum vulgare subsp. distichum var. nudum & Desnuda & Cebada de dos carreras desnuda \\
Hordeum vulgare subsp. vulgare var. nudum & Desnuda & Cebada de seis carreras desnuda \\
\hline
\end{tabular}

Tab. 1. Taxones estudiados en el presente trabajo. Todas las muestras de semillas proceden de la colección de referencia (carpoteca) del Centro de Ciencias Humanas y Sociales (CSIC, Madrid). 

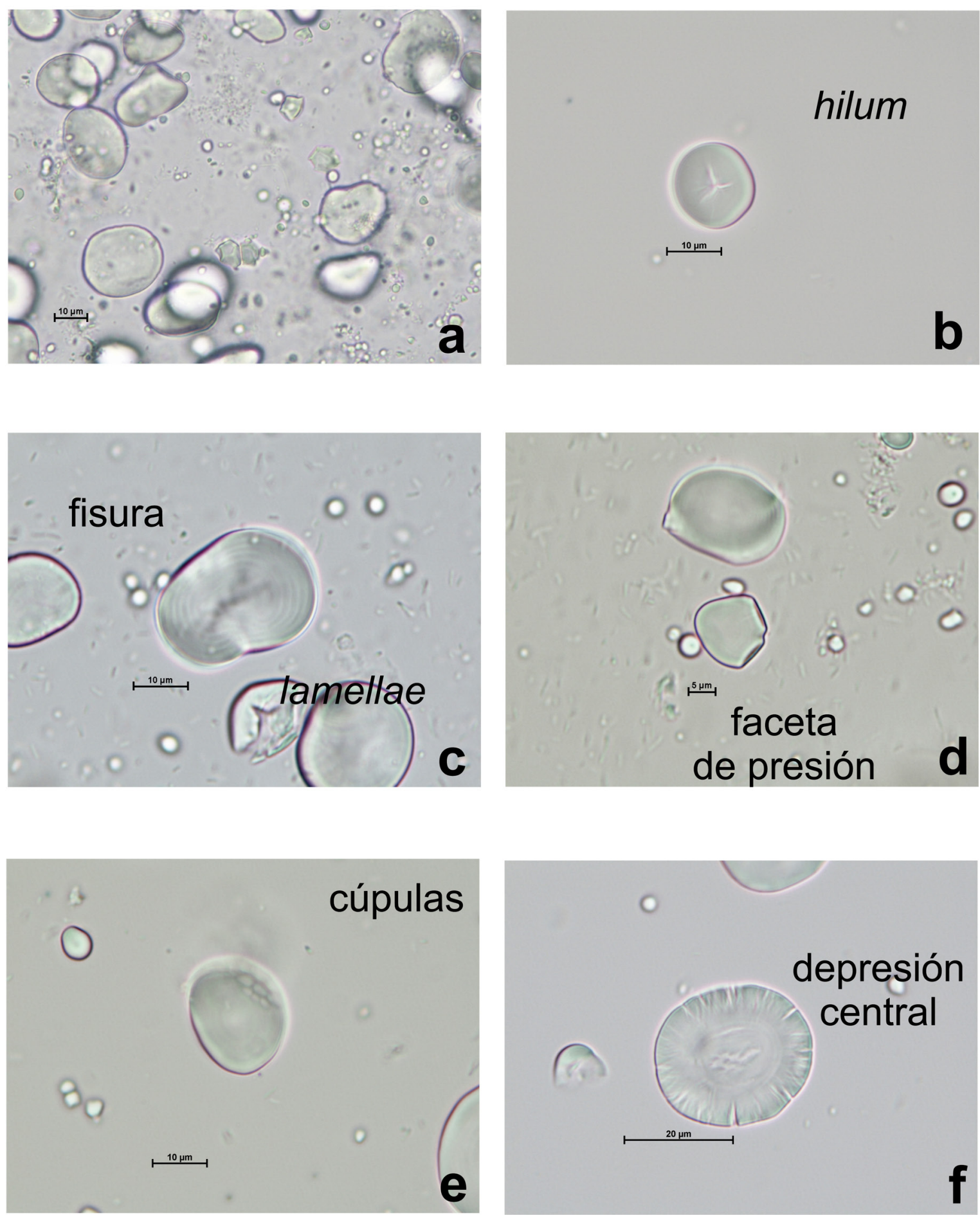

Fig. 1. Variables morfológicas analizadas en los granos de almidón. a: variabilidad morfológica (Hordeum vulgare subsp. distichum); b: hilum (Triticum aestivum); c: fisura y lamellae (H. vulgare subsp. vulgare); d: faceta de presión (H. vulgare subsp. distichum); e: cúpulas (T. dicoccum); f: depresión central (T. aestivum) (fotografías tomadas en microscopio óptico: Francisco Javier Aceituno, Laboratorio de Arqueología, Universidad de Antioquia). 
ton 2006; Hoslt et al. 2007; Giovannetti et al. 2008). Las primeras miden la longitud de cada grano (eje más largo), anchura (eje perpendicular al anterior) y diámetro (solo en granos circulares). Las cualitativas describen la morfología de los granos en un plano bidimensional o tridimensional (Fig. 1a), según una tipología consensuada (Piperno 2009): campana (forma semiesférica con extremo distal terminado en un plano o 'corona' simple o bifacetado), circular (diámetro igual en cualquiera de sus puntos), alargado (con forma irregular), irregular (sin morfología definida), ovalado (forma redondeada con ejes mayor y menor), poliédrico (angular con caras o 'facetas de presión' visibles), poligonal (angular sin facetas visibles) y reniforme (forma de riñón, similar a la ovalada, pero sin ejes claramente definidos).

Hay más variables cualitativas. Unas dependen de la apertura o cierre del hilum: cuando es abierto y, por lo tanto visible, se considera su posición (céntrica o excéntrica) y forma (arco, cruz, estrellado, puntiforme, lineal, cicatriz) (Fig. 1b). Otras valoran si hay fisuras o pequeñas grietas en la superficie del grano debidas a su degradación. Tienen en cuenta su posición y forma, describiéndose igual que el hilum, aunque las fisuras pueden ser radiales (Fig. 1c). Las terceras señalan las facetas de presión (planos geométricos que permiten agrupar los granos en los plástidos de las células) y la cantidad de planos visibles (Fig. 1d). Por último, se atiende a la ausencia/presencia de lamellae, cavidades o depresiones centrales (pequeñas, presentes en algunas caras) o cúpulas (Fig. 1c, e, f). En la caracterización final de los granos excluimos la 'Cruz de Malta', únicamente observable bajo luz polarizada, dado que en un análisis exploratorio no resultó una variable discriminatoria.

El análisis del conjunto de datos disponible se efectuó mediante estadística multivariante según las directrices del International Code for Starch Nomenclature (ICSN 2011) y de otros estudios previos (Torrence y Conway 2006). Primero, mediante análisis de conglomerados jerárquico (cluster analysis), una técnica multivariante exploratoria, se agruparon casos (taxa) y variables (parámetros morfológicos cuantitativos de granos ovalados y campaniformes por ser los más representativos en todas las muestras, Tabs. 2 y 5) por su similaridad.

Se utilizó el método de Ward (1963) de aglomeración y la correlación de Pearson como medida de distancia. A continuación en los granos ovalados, cuyo número de variables ornamentales

\begin{tabular}{|l|c|c|c|c|c|c|c|}
\hline \multicolumn{1}{|c|}{ Taxón } & Ovalado & Reniforme & $\begin{array}{c}\text { Ovalado } \\
\text { pequeño }\end{array}$ & Campana & $\begin{array}{c}\text { Campana } \\
\text { bifacetada }\end{array}$ & Circular & Poliédrico \\
\hline T. aestivum & $55,3-11,4$ & - & $10,4-4,8$ & $8,9-3,6$ & $9,5-5,2$ & $27,8-4,2$ & $12,5-4,5$ \\
T. dicoccum & $23,4-12,9$ & $29,4-27$ & $10,8-5,6$ & $12,5-3,3$ & $11,3-4,6$ & $11-3,6$ & $6,5-4,1$ \\
T. durum & $48,3-11,5$ & $34,1-25,3$ & $10,2-5,6$ & $11,9-4,8$ & $12,6-5,2$ & $30-5,6$ & $7,3-4,1$ \\
T. monococcum & $30,1-13,3$ & - & $11,1-4,4$ & $19,2-5$ & $18,6-4$ & $24,4-7,6$ & 15,6 \\
T. turgidum & $32-13,5$ & - & $10,1-7,2$ & $17-4,8$ & $12,3-3,5$ & $31,6-5,6$ & $6,4-3$ \\
\hline
\end{tabular}

Tab. 2. Variables métricas (rango en $\mu \mathrm{m}$ ) y cualitativas en los granos de almidón identificados en especies de Triticum.

\begin{tabular}{|l|l|l|l|l|l|l|l|l|l|l|}
\hline \multicolumn{1}{|c|}{ Taxón } & Ovalado & $\begin{array}{c}\text { Ovalado } \\
\text { uniface- } \\
\text { tado }\end{array}$ & $\begin{array}{c}\text { Ovalado } \\
\text { bifacetado }\end{array}$ & $\begin{array}{c}\text { Reni- } \\
\text { forme }\end{array}$ & $\begin{array}{l}\text { Ovalado } \\
\text { pequeño }\end{array}$ & Campana & $\begin{array}{c}\text { Campana } \\
\text { bifacetada }\end{array}$ & Circular & $\begin{array}{c}\text { Polié- } \\
\text { drico }\end{array}$ & $\begin{array}{c}\text { Tronco- } \\
\text { cónico }\end{array}$ \\
\hline T. aestivum & 14,5 & 0 & 0 & 0 & 46,6 & 6,7 & 2,2 & 28 & 19,2 & 0 \\
T. dicoccum & 23 & 0 & 0 & 1,2 & 30,1 & 20 & 6,7 & 13,9 & 4,2 & 0 \\
T. durum & 25,6 & 0 & 0 & 3,3 & 55,1 & 5,6 & 2,2 & 6,1 & 2 & 0 \\
T. monococcum & 25,7 & 0,3 & 0,3 & 0 & 48,6 & 10,8 & 1,3 & 12,8 & 0,3 & 0,3 \\
T. turgidum & 16,8 & 0 & 0 & 0 & 41,6 & 17,7 & 5,3 & 15 & 3,5 & 0,3 \\
\hline
\end{tabular}

Tab. 3. Porcentaje de morfotipos de granos de almidón en las especies de Triticum. 


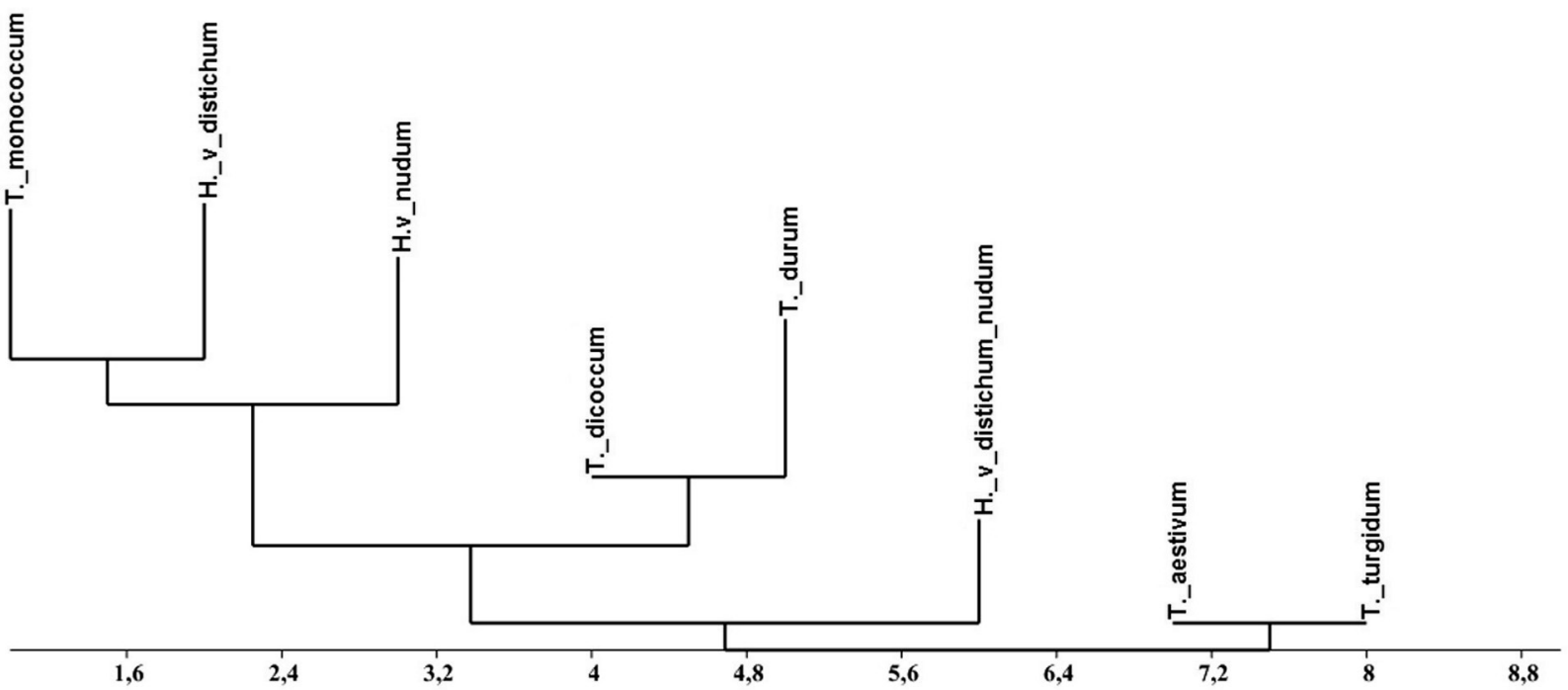

Fig. 2. Dendrograma correspondiente al análisis de conglomerados jerárquico de los granos de almidón.

es mayor, se realizó un análisis de conglomerados de K-medias, como método de agrupación de casos (taxa), basado en la distancia euclídea entre ellos en un conjunto de variables binarias: presencia y/o ausencia de cúpulas, depresión, hilum, fisuras, lamellae y facetas. Finalmente, se aplicó un segundo análisis de conglomerados jerárquico, parecido al primero, tomando como variables los parámetros cualitativos (Tabs. 3 y 6) y usando el coeficiente o índice de similitud de Bray-Curtis como medida de distancia (Fig. 2). Al conceder mayor peso a los valores altos resulta una opción menos sesgada que la distancia euclídea (Bray y Curtis 1957).

\section{RESULTADOS}

La tabla 2 indica los valores de las variables métricas de cada morfotipo identificado en los

\begin{tabular}{|l|c|c|c|c|c|c|}
\hline \multicolumn{1}{|c|}{ Taxón } & Ovalado & $\begin{array}{c}\text { Ovalado } \\
\text { pequeño }\end{array}$ & Campana & $\begin{array}{c}\text { Campana } \\
\text { bifacetada }\end{array}$ & Circular & Poliédrico \\
\hline T. aestivum & 22,2 & 44,4 & 0 & 0 & 27,8 & 5,5 \\
T. dicoccum & 3,8 & 26,9 & 23,1 & 11,5 & 30,8 & 3,8 \\
T. durum & 38,9 & 13,9 & 22,2 & 11,1 & 13,9 & 0 \\
T. monococcum & 7,7 & 23,1 & 46,2 & 0 & 15,4 & 7,7 \\
T. turgidum & 19 & 38,1 & 0 & 9,5 & 33,3 & 0 \\
\hline
\end{tabular}

Tab. 4. Porcentaje de hilum abierto en las especies de Triticum.

\begin{tabular}{|l|c|c|c|c|c|c|c|}
\hline \multicolumn{1}{|c|}{ Taxón } & Ovalado & Reniforme & $\begin{array}{c}\text { Ovalado } \\
\text { pequeño }\end{array}$ & Campana & $\begin{array}{c}\text { Campana } \\
\text { bifacetada }\end{array}$ & Circular & Poliédrico \\
\hline subsp. distichum & $34,2-12,9$ & $30-15,6$ & $11,4-4,2$ & $12,3-3,1$ & $16-5,5$ & $30,6-4$ & $10,9-4$ \\
subsp. distichum var. nudum & $37,6-34,6$ & - & $12-9,5$ & $9,9-4,2$ & $7-3$ & $22-5$ & $7,3-3,7$ \\
subsp. vulgare var. nudum & $44,2-12,7$ & $34,6-25,8$ & $10,2-6,2$ & $18,3-4,2$ & $7,9-4$ & $14,3-5,2$ & $8,6-3,6$ \\
\hline
\end{tabular}

Tab. 5. Variables métricas (rango en $1 \mathrm{~m}$ ) y cualitativas en los granos de almidón identificados en variedades de Hordeum vulgare. 


\begin{tabular}{|l|r|r|c|c|c|c|c|c|c|c|c|l|}
\hline \multicolumn{1}{|c|}{ Taxón } & $\mathbf{1}$ & $\mathbf{2}$ & $\mathbf{3}$ & $\mathbf{4}$ & $\mathbf{5}$ & $\mathbf{6}$ & $\mathbf{7}$ & $\mathbf{8}$ & $\mathbf{9}$ & $\mathbf{1 0}$ & $\mathbf{1 1}$ & $\mathbf{1 2}$ \\
\hline subsp. distichum & 11,2 & 7,6 & 6,5 & 2,5 & 3,2 & 37,2 & 10,1 & 6,3 & 10,1 & 5,1 & 0 & 0 \\
subsp. distichum var. nudum & 24,4 & 2,5 & 1,3 & 0 & 0 & 34,2 & 12,6 & 1,9 & 15,5 & 3,8 & 2,5 & 1,2 \\
subsp. vulgare var. nudum & 7,4 & 14,3 & 9,2 & 1,4 & 3 & 29,3 & 10,1 & 6,2 & 9,1 & 6,5 & 1,7 & 1,6 \\
\hline
\end{tabular}

Tab. 6. Porcentaje de morfotipos de granos de almidón en variedades de Hordeum vulgare. 1= Ovalado; 2= Ovalado unifacetado; 3= Ovalado bifacetado; 4= Ovalado trifacetado; 5= Reniforme; 6= Ovalado pequeño; 7= Campana; 8= Campana bifacetada; 9= Circular; 10= Poliédrico; 11= Irregular; 12= Troncocónico.

\begin{tabular}{|l|c|c|c|c|}
\hline \multicolumn{1}{|c|}{ Taxón } & Ovalado & Reniforme & Campana & Circular \\
\hline subsp. distichum & 10 & 31,6 & 21,1 & 60 \\
subsp. distichum var. nudum & 7,7 & 0 & 0 & 0 \\
subsp. vulgare var. nudum & 20 & 0 & 0 & 0 \\
\hline
\end{tabular}

Tab. 7. Porcentaje de hilum abierto en variedades de Hordeum vulgare.

granos de almidón de las 5 especies de Triticum estudiadas. Las medidas de los ovalados unifacetados y bifacetados están incluidas en los ovalados. La tabla 3 recoge los porcentajes de cada tipo morfológico y la tabla 4 el del hilum abierto en las mismas especies y morfotipos.

Las tablas 5, 6 y 7 ofrecen los mismos datos señalados en las anteriores respecto a las 3 variedades estudiadas de cebada (Hordeum vulgare).
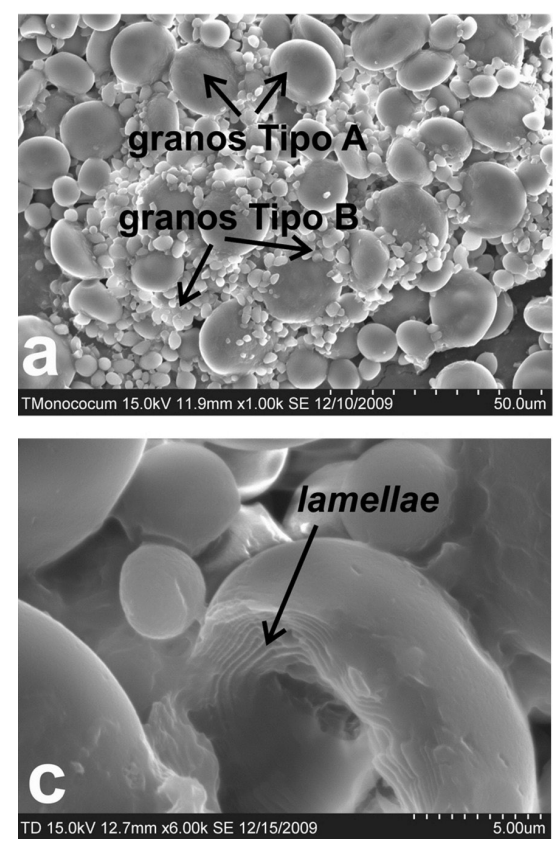

Las medidas de los ovalados unifacetados, bifacetados y trifacetados están incluidas en los ovalados (Tab. 5). Los valores porcentuales de otras variables cualitativas (depresión central, lamellae, cúpulas, fisuras, facetas de presión) se citarán directamente en el texto.

Los granos de almidón de Triticum son bimodales y polimorfos (Tab. 2): se dividen por su longitud en grandes ( $>10 \mu \mathrm{m}$, tipos $\mathrm{A})$ y peque-
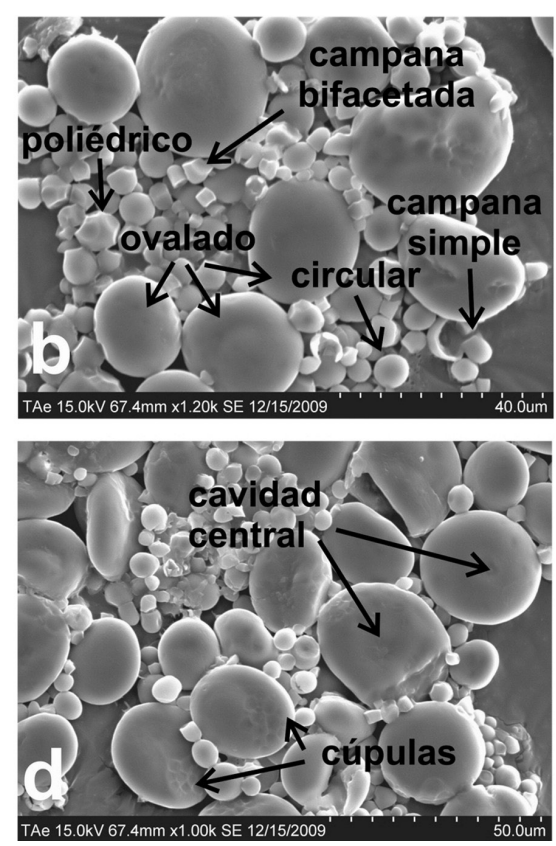

Fig. 3. Granos de almidón del género Triticum. a: granos tipo A y B (T. monococcum) ; b: morfotipos (T. aestivum); c: lamellae (T. dicoccum); d: cavidad central y cúpulas ( $T$. aestivum) (fotografías tomadas en microscopio electrónico: Óscar García Vuelta, MicroLab, CCHS, CSIC). 
ños $(<10 \mu \mathrm{m}$, tipos B) (Wang et al. 1997) y agrupan hasta 7 morfotipos. La relación entre tamaño y morfología es evidente: los granos tipo A son principalmente ovalados y en menor medida reniformes y en los de tipo B predominan las formas ovaladas pequeñas, poliédricas y campaniformes (Fig. 3a). No obstante caben precisiones a nivel específico. Los granos ovalados más grandes se producen en Triticum aestivum (Fig. 3b) y T. durum. Triticum monococcum se diferencia del resto por el mayor tamaño de los campaniformes, campaniformes bifacetados y poliédricos (Fig. 3a, Tab. 2). Los granos circulares son tanto de tipo A como B, siendo más pequeños en Triticum dicoccum que en el resto.

Predominan claramente los morfotipos ovalados (tipo A y B) (Tab. 3): suman más del 50\% en las 5 especies estudiadas. La variación intraespecífica en la muestra de los granos campaniformes, campaniformes bifacetados, circulares, poliédri$\cos$ (Fig. 3b) y reniformes es muy sutil.

Por especies, en Triticum dicoccum y T. turgidum los campaniformes ocupan el segundo y tercer lugar respectivamente. En el resto, las formas circulares son las más abundantes tras las ovaladas. Si se suman ambos tipos de campana, su porcentaje puede incluso superar a los granos ovalados (tipo A), como sucede en Triticum dicoccum y T. turgidum. Los porcentajes de granos poliédricos y reniformes son muy pequeños. Solo en Triticum aestivum su peso es mayor que el de los campaniformes y ovalados (tipo A). Se concluye que Triticum dicoccum, T. monococcum y T. turgidum se comportan de forma similar, T. aestivum se diferencia por el mayor porcentaje de los poliédricos y T. durum por el de granos ovalados (80\%). Predomina claramente el tamaño del tipo B: tipo A $<30 \%$.

En las variables cualitativas, hay tendencias y similitudes entre las especies analizadas en Triticum. La primera característica común es el morfotipo redondeado, salvo los almidones poliédricos de contorno angular. La depresión o cavidad central (Figs. 3d y 4a), las cúpulas (Figs. 3d y 4a) y las lamellae (Fig. 3c) se asocian únicamente a las formas ovaladas, reniformes y circulares.

En los granos ovalados (tipo A), la depresión central varía entre especies: del 50\% en Triticum turgidum a su ausencia en T. durum; en las 3 restantes, el valor medio es del 30\%. Las cúpulas también presentan valores disímiles: en Triticum monococcum no se observaron; en $T$. aestivum 4,2\%; en T. turgidum 22,3\%; en T. durum $30 \%$ y
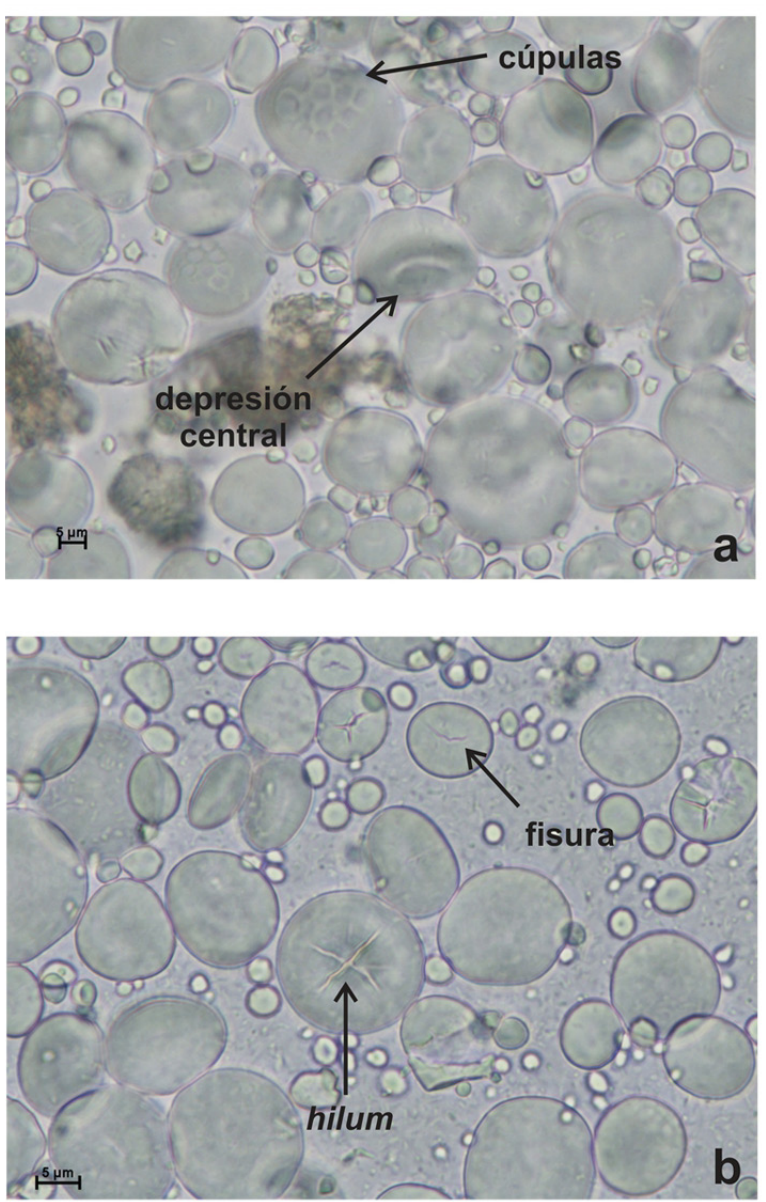

Fig. 4. Granos de almidón del género Triticum al microscopio óptico. a: depresión central y cúpulas (T. durum); b: fisura e hilum (T. aestivum) (fotografías: Francisco Javier Aceituno, Laboratorio de Arqueología, Universidad de Antioquia).

en $T$. dicoccum $36,8 \%$. Los valores de lamellae en los granos ovalados oscilan entre $12,5 \%$ (Triticum aestivum, T. monococcum) y 50\% (T. turgidum) con $31,6 \%$ para $T$. dicoccum y $40 \%$ para T. durum. En resumen, las especies de Triticum con los valores más altos de las tres variables cualitativas citadas son Triticum turgidum, T. durum y $T$. dicoccum. Las que los tienen más bajos son T. monococcum y T. aestivum. Se observan varias facetas de presión en los granos poliédricos, incluyendo el morfotipo troncocónico, y en los ovalados (unifacetados y bifacetados). Los campaniformes son simples o bifacetados.

El porcentaje de hilum abierto en Triticum (Tab. 4; Fig. 4b) es bajo, sin superar el 30\% en 
la suma total de morfotipos por especie: $29,6 \%$ T. turgidum; $28,6 \%$ T. durum; $24,7 \%$ T. dicoccum; $19,3 \%$ T. aestivum; $17,3 \%$ T. monococcum. En las 5 especies analizadas, los mayores valores se dan en los granos ovalados (tipos A y B), campaniformes (simples y bifacetados), circulares $\mathrm{y}$, a distancia, poliédricos. La especie con mayor diferencia en el comportamiento del hilum es Triticum aestivum. En las fisuras los valores también son bajos $(<20 \%)$ : 17,2\% Triticum aestivum; $14,6 \%$ T. monococcum; $11,3 \%$ T. turgidum; $5,5 \%$ T. durum; 3,8\% T. dicoccum. Las fisuras (Fig. 4b) están claramente asociadas a los granos ovalados (tipo A), los circulares y, en menor medida, a los de campana. En el caso de las fisuras, se trata de una variable que depende de factores relacionados con la propia degradación de los granos de almidón y el procesamiento de los alimentos (Henry et al. 2009; Piperno 2009).

Los granos de almidón de Hordeum vulgare pertenecen igualmente al grupo de especies bimodales y mantienen la misma relación entre tama- ño y morfología que los de Triticum. Se dividen también en granos de tipo A $(<30 \%)$ y tipo B (Tab. 5, Fig. 5a), coincidiendo con estudios previos (Vasanthan y Hoover 2009). Las formas ovaladas, reniformes y circulares representan a los tipos A y las restantes a los tipos B.

Las 3 variedades de Hordeum vulgare son de tamaño más homogéneo que las de Triticum (Tab. 5) y sus porcentajes también son más parecidos entre si. El peso de cada morfotipo en el total de cada variedad es similar al de las especies de Triticum: los granos ovalados (tipos A y B) suman más del 50\% (Tab. 6; Fig. 5b) seguidos de campaniformes (simples y bifacetados), circulares, poliédricos y reniformes, incluyendo el morfotipo troncocónico y ovalado (unifacetados $\mathrm{y}$ bifacetados) (Figs. 5c, 6a).

Las variables cualitativas en Hordeum vulgare se comportan de forma similar a Triticum con una relación entre granos redondeados y angulares muy semejante. La depresión central, las cúpulas y las lamellae (Figs. 5d, 6b) también se asocian principalmente a los granos ovalados, incluyendo
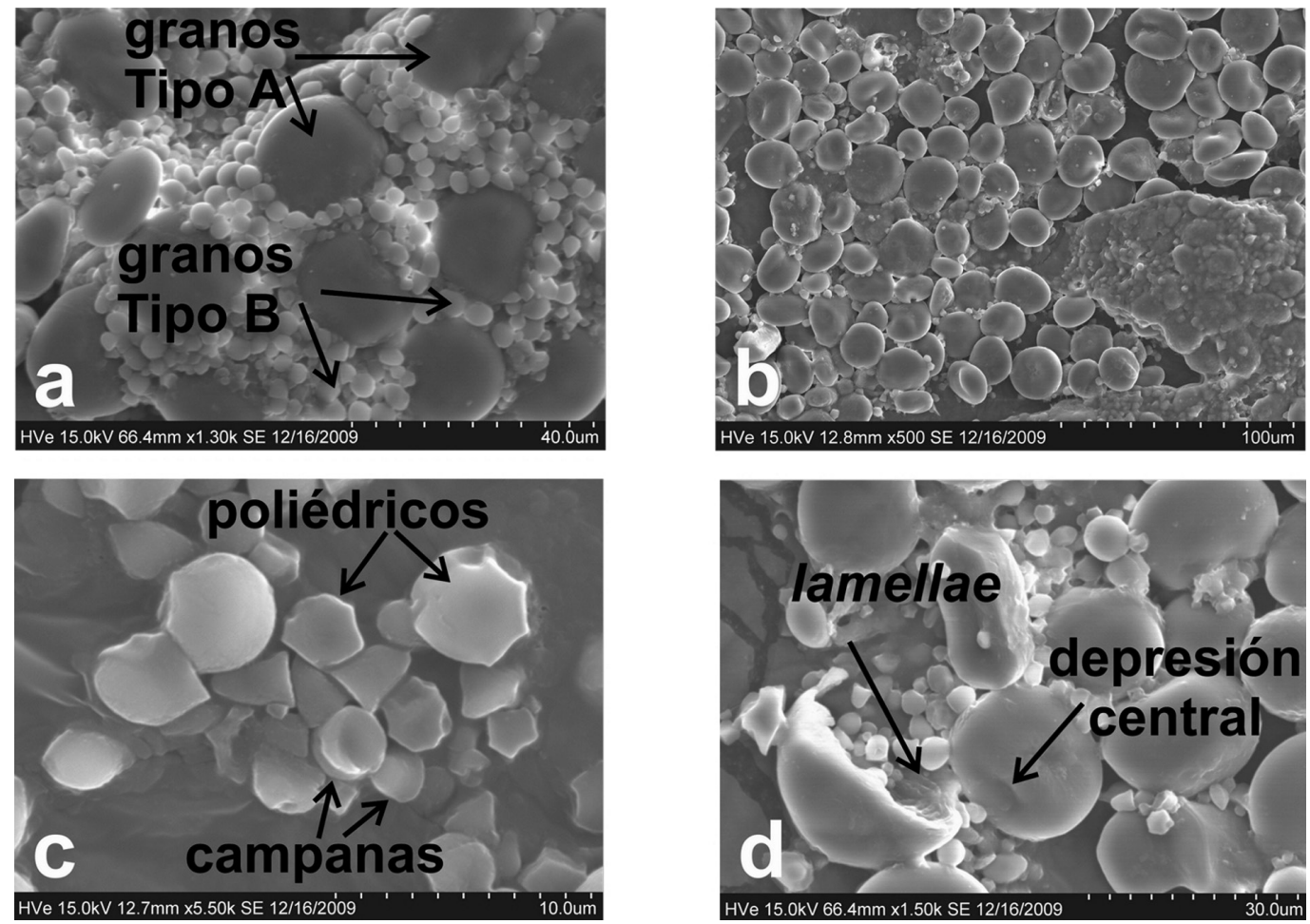

Fig. 5. Granos de almidón de Hordeum vulgare subsp distichum. a: granos tipo A y B; b: variabilidad morfológica; c: morfotipos poliédrico y tipo campana; d: lamellae y depresión central (fotografías tomadas en microscopio electrónico: Óscar García Vuelta, MicroLab, CCHS, CSIC). 

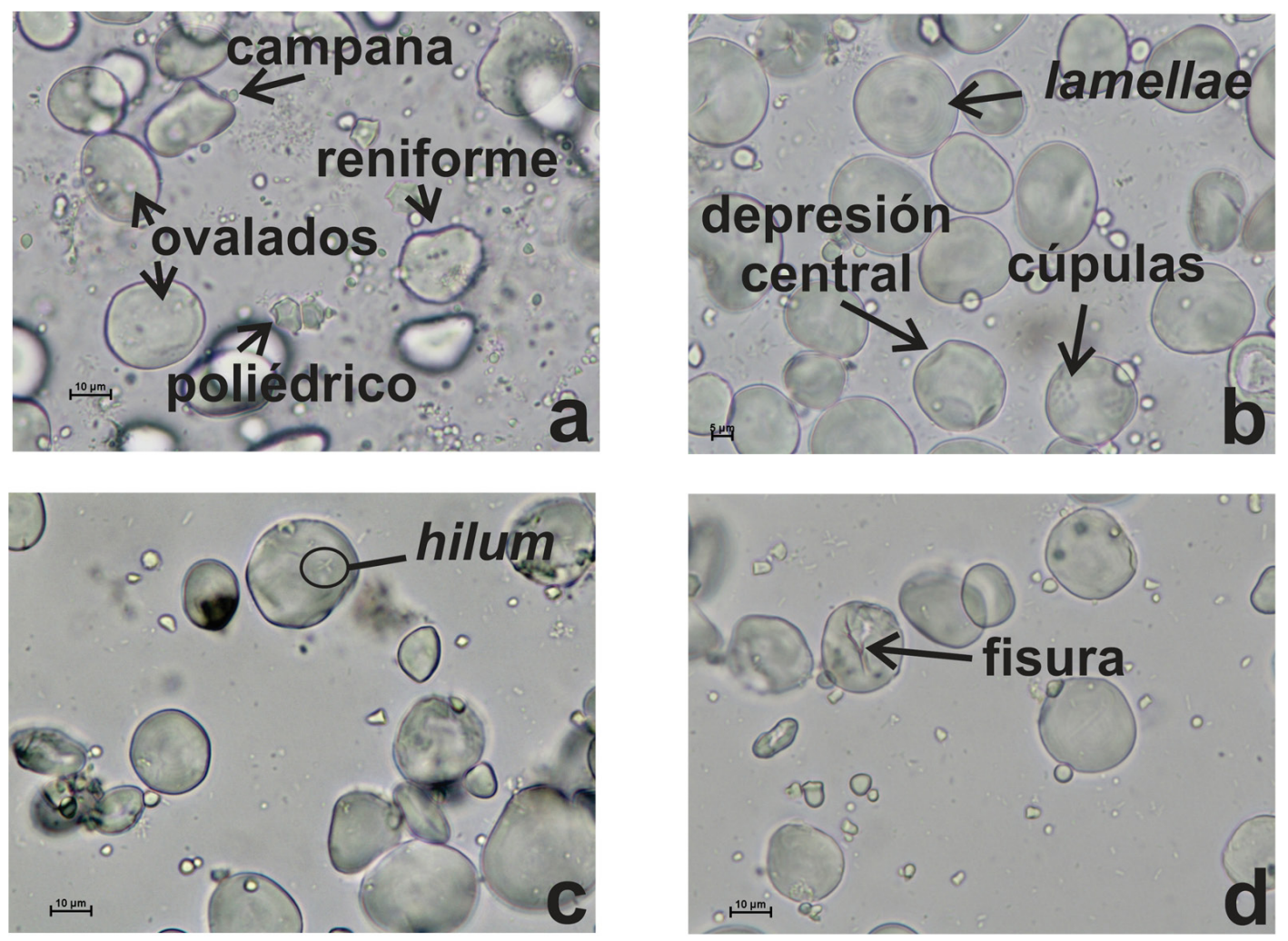

Fig. 6. Granos de almidón de Hordeum vulgare al microscopio óptico. a: morfotipos (subsp. distichum var. nudum); b: depresión central, lamellae y cúpulas (subsp. distichum); c: hilum (subsp. distichum var. nudum); d: fisura (subsp. distichum var. nudum) (fotografías: Francisco Javier Aceituno, Laboratorio de Arqueología, Universidad de Antioquia).

a los facetados y, en menor medida, a los circulares. La depresión central en los ovalados (tipo A) es del orden del 20\%: 13,3\% en la subsp. distichum; $15,4 \%$ en la subsp. distichum var. nudum y $20 \%$ en la subsp. vulgare var. nudum. Las cúpulas oscilan entre 10-25\%: 10\% en la subsp. distichum; $23,1 \%$ en la subsp. distichum var. nudum y $20 \%$ en la subsp. vulgare var. nudum. En cambio hay más lamellae que en Triticum: con valores $=$ al $66,7 \%$ en la subsp. distichum; $73,1 \%$ en la subsp. distichum var. nudum y $50 \%$ en la subsp. vulgare var. nudum. Las facetas de presión se comportan como en Triticum salvo por aparecer en un porcentaje significativo de granos ovalados (tipo A): $16,7 \%$ en la subsp. Distichum; $3,8 \%$ en la subsp. distichum var. nudum y $25 \%$ en la subsp. vulgare var. nudum.

En conjunto, el porcentaje de granos con hilum abierto (Fig. 6c) es algo menor que en Triticum: entre $7,7 \%$ y $31,6 \%$ (Tab. 7). En las variedades de cebada con menos granos de almidón con hilum abierto (subsp. distichum var. nudum y subsp. vulgare var. nudum) el rasgo se asocia a los granos ovalados (tipo A). En la subsp. distichum corresponde a granos reniformes, seguidos de circulares, campaniformes y ovalados (tipo A). La presencia de fisuras (Fig. 6d) es similar también a Triticum: 9,6\% en la subsp. Distichum; $2,8 \%$ en la subsp. distichum var. nudum y $20,4 \%$ en la subsp. vulgare var. nudum.

\section{DISCUSIÓN Y CONCLUSIONES}

\subsection{Variables métricas y cualitativas}

Las características comunes de la morfología de los granos de almidón (Tabs. 2-4) de las 5 especies analizadas del género Triticum dificulta 
inicialmente su identificación en el registro arqueobotánico (Piperno et al. 2004; Zhong-Min et al. 2008; Piperno 2009). Esta limitación taxonómica se agrava, porque las diferencias detectadas en la mayoría de las variables entre unas especies y otras son estadísticas (Lentfer et al. 2002; Wilson et al. 2010): no cabe una discriminación específica según una variable particular ya que los valores se solapan en sus rangos.

No obstante, la presencia o ausencia de alguna variable o rasgo puede ser determinante a ese respecto, por ejemplo, Triticum durum y $T$. diccoccum son las únicas especies de trigo estudiadas con granos reniformes; en los granos ovalados (tipo A) de T. durum no hay depresión central, ni cúpulas en los de T. monococcum; falta el hilum abierto en los granos poliédricos de $T$. durum y $T$. turgidum y en los campaniformes de $T$. aestivum y T. turgidum.

Además los granos de almidón de Triticum monococcum tienden a ser mayores que en el resto de las especies y es el único trigo con granos ovalados unifacetados y morfotipo troncocónico. T. aestivum tiene los mayores granos ovalados de todos los morfotipos y especies y un alto peso porcentual de los granos poliédricos y circulares, muy distante del de las otras. Destacamos la importancia del morfotipo campana en T. turgidum.

En otras variables cualitativas, aunque se sigue también un patrón común, se observa quizá mayor disparidad interespecífica con porcentajes muy altos o ausencias: depresión central en Triticum turgidum (50\%) y T. durum ( $0 \%$ ) o cúpulas en $T$. monococcum $(0 \%)$ y $T$. aestivum $(4,2 \%)$, cuando en las otras tres especies son del $22-36 \%$. Algo parecido ocurre con las lamellae: valores altos en Triticum turgidum y T. durum y bajos en T. monococcum y T. aestivum.

Resulta muy difícil la separación intraespecífica de las variedades de Hordeum vulgare y Triticum, dado que su comportamiento es muy homogéneo en las tres variedades estudiadas (Tabs. 5-7). Una primera aproximación a ese objetivo sería la separación de los géneros Triticum y Hordeum según la morfología de sus almidones. Al pertenecer ambos a la familia Poaceae (tribu Triticeae) y estar genéticamente emparentados (Reichert 1913; Piperno 2009) sus similitudes son amplias. Sin embargo sus diferencias permiten separar los granos de almidón de cada uno:
1) los granos ovalados $>50 \mu \mathrm{m}$ están asociados a Triticum aestivum; ninguna otra especie del mismo género o variedad de Hordeum vulgare alcanza tallas similares;

2) hay más lamellae en las variedades de cebada que en las especies de trigo;

3) un porcentaje considerable de granos ovalados (tipo A) en la cebada presenta una o dos facetas de presión, rasgo prácticamente ausente en las especies de trigo analizadas;

4) el porcentaje de hilum abierto es menor en los trigos que en la cebada;

5) el hilum abierto aparece en los granos poliédricos de Triticum aestivum, T. dicoccum, T. monococcum pero no en los de las variedades de cebada;

6) los granos reniformes de las especies de trigo no tienen hilum abierto. Hordeum vulgare subsp. distichum es la única variedad de cebada con el hilum visible en los granos reniformes, campaniformes y circulares.

\subsection{Análisis estadístico}

El cladograma resultante del análisis de conglomerados jerárquico que agrupaba las variables como parámetros morfológicos métricos (referidos a los granos ovalados y campaniformes por ser los más representativos) no separó géneros ni especies entre sí. Como ya se comentó, los rangos de tamaño de los morfotipos escogidos se solapan entre sí (Tabs. 2 y 5), lo que impide una discriminación genérica o específica de los taxa.

El análisis de conglomerados de K-medias, tomando en consideración un conjunto de variables ornamentales en los granos ovalados, tampoco discriminó géneros y especies al aparecer tales variables en todos los taxa.

El segundo análisis de conglomerados jerárquico, que tomaba como variables los parámetros cualitativos (Tabs. 3 y 6), sí diferencia con nitidez dos clados de primer orden (Fig. 2). El primero incluye Triticum aestivum y T. turgidum y el segundo el resto de taxa.

En el primero de los clados, el porcentaje de granos ovalados tipo A $(<20 \%$ Tab. 3$)$ de ambas especies las diferencia claramente de las otras tres especies del género. Las dos especies de Triticum comparten, también, ser las únicas sin granos ovalados facetados y reniformes y con granos campaniformes sin hilum abierto (Tab. 4). 
El segundo clado se subdivide en dos de segundo orden. El primer subclado solo incluye a Hordeum vulgare subsp. distichum var. nudum y el segundo al resto de taxa: las 3 especies de trigo y 2 variedades más de cebada. Hordeum vulgare subsp. distichum var. nudum es la variedad de cebada con más granos ovalados no facetados tipo A ( $>20 \%$ Tab. 6): las otras dos ni siquiera alcanzan el 10\%. A diferencia de ellas carece de granos reniformes y cuenta con porcentajes muy bajos de ovalados facetados y campanas bifacetadas.

El segundo subclado se subdivide en otros dos de tercer orden. Uno engloba a Triticum dicoccum y $T$. durum y el otro a $T$. monococcum y las dos variedades de cebada restantes. La escanda melliza y el trigo duro son las únicas especies de trigo con granos reniformes (Tab. 3). Probablemente esta sea la variable que las agrupa en el mismo clado. También comparten carecer de troncocónicos y ovalados facetados.

El segundo subclado de tercer orden es más confuso: aisla a Hordeum vulgare subsp. vulgare var. nudum y aúna en un clado de cuarto orden a Triticum monococcum y Hordeum vulgare subsp. distichum.

La cebada de seis carreras desnuda tiene más granos ovalados (tipo $\mathrm{A}<10 \%$ ) que las otras dos variedades $(>10 \%)$ y los porcentajes de ovalados facetados (especialmente los unifacetados) son relativamente elevados (14,3\% Tab. 6). La escaña es el único trigo con ovalados facetados (Tab. 3). Este parámetro, posiblemente el discriminante respecto a los otros trigos, la sitúa junto a la cebada de seis carreras desnuda citada y la de dos carreras vestida también con altos porcentajes de ovalados facetados en su conjunto (Tab. 6). El hilum abierto en los granos reniformes, campaniformes y circulares de la cebada de dos carreras vestida (Tab. 7) es un factor más de separación entre esta variedad y la de seis carreras desnuda.

En definitiva cabe la separación intragenérica e intraespecífica en Triticum y Hordeum según la morfología de los granos de almidón de sus respectivos taxa. Parámetros muy significativos a este respecto son el porcentaje de granos ovalados (tipo A), la ausencia/presencia de granos reniformes y ovalados facetados y, en orden decreciente de importancia, el hilum abierto o no en algunos morfotipos de almidón.

\subsection{Síntesis crítica de los estudios sobre almidones en la Península Ibérica}

Las muchas posibilidades diagnósticas de los almidones en los taxa estudiados de los géneros Triticum y Hordeum no evitan tener que contar para la identificación de granos de almidón recuperados en contextos arqueológicos con datos arqueobotánicos de apoyo como macrorrestos (semillas), fitolitos, granos de polen o información de fuentes o crónicas escritas (Kealhofer et al. 1999; Alonso et al. 2003; Coil et al. 2003; Horrocks 2005; Piperno 2006, 2009; Hardy et al. 2009).

Los estudios bioarqueológicos suelen basar la determinación taxonómica de los almidones recuperados en contextos arqueológicos en su caracterización morfológica y comparación con otros de plantas actuales. Ello requiere la creación de colecciones de referencia (Seidemann 1966; Therin et al. 1997; Piperno 2006; Torrence y Barton 2006; Henry et al. 2009), recurso ampliado recientemente a una identificación a partir de datos morfométricos y análisis multivariantes (Lentfer et al. 2002; Wilson et al. 2010). De lo contrario, solo se logran descripciones morfológicas a nivel de tipología de los granos de almidón, sin identificar la especie o taxón productor. Esto último ha sido la constante en las investigaciones pioneras sobre análisis de almidones en yacimientos arqueológicos peninsulares, las cuales no superaron la identificación taxonómica a nivel de la tribu Triticeae (Blasco et al. 1999; Juan-Tresserras 2000c; Yáñez et al. 2002)(2).

El interés de introducir este nuevo registro arqueobotánico en la bibliografía peninsular fue muy evidente y promisorio en su estado inicial pero, en la actualidad, resulta insuficiente. Lo es, precisamente, porque hay una tendencia general a asumir una relación directa entre presencia de almidones (cálculo dental, contenido de recipientes, etc.) y especies cultivadas. Solo una caracterización morfológica, como la aquí presentada, permite saber si este ha sido el caso. Como los estudios sobre granos de almidón emprendidos hasta el momento en la Península Ibérica no aportan datos sobre las variables consideradas hemos de pensar que se identificaron almidones sin más, procedentes de especies cultivadas o no, pues hay

(2) Véase n. 1. 
almidones en numerosas partes y estructuras de las plantas.

Hay que tener en cuenta que las operaciones de descascarillado y molienda de los cereales contribuyen a una mayor concentración de los granos de almidón y pueden provocar alteraciones microscópicas en los mismos (Mock y Dick 1991). Residuos que contenían almidones con alteraciones derivadas de la molienda y el malteado de los granos de cereal (lamellae parcialmente digerida, fisuras, depresiones, etc.) se han interpretado como resultado de su fermentación en la elaboración de cervezas (Juan-Tresseras 1998, 2000c; Alonso et al. 2003)(3) sin evaluar suficientemente otras posibilidades. Incluso en material fresco, como el nuestro, procedente de una colección de referencia las fisuras o depresiones son uno rasgos cualitativos distinguibles, relacionado con determinadas especies o variedades de trigos y cebadas.

De igual manera se afirma (Juan-Tresserras 2000c)(4) que la gelatinización del almidón indica que los cereales se calentaron húmedos, como otra prueba, al parecer irrefutable, de su uso en la elaboración de una bebida espirituosa como la cerveza. Es cierto que los procesos de molienda, secado, prensado y cocinado pueden producir cambios pre y postdeposicionales en los almidones, debidos a su naturaleza bioquímica. A su vez, los residentes en paleosuelos pueden sufrir ataques enzimáticos o por organismos consumidores microscópicos como bacterias u hongos (Lineback y Wongsrikasem 1980; Lentfer et al. 2002; Babot 2003; Haslam 2004; Horrocks 2005; Horrocks et al. 2004). Esos procesos pueden alterar o destruir algunas características morfológicas de los almidones, habiéndose demostrado que su calentamiento en presencia de agua rompe los anillos cristalinos interiores de su estructura, produciendo su gelatinización, una forma de complejo viscoso con agua (McGee 1984). Sin embargo, los estudios sobre el efecto del cocinado de los almidones en su forma, tamaño y otras variables cualitativas visibles al microscopio óptico son muy escasos y focalizados en unas pocas especies o en métodos especializados de cocina (Samuel 2000; Babot 2003; Lamb y Loy 2005).

Recientemente, Henry et al. (2009) experimentaron con la alteración de los granos de

(3) Véase n. 1.

(4) Véase n. 1. almidón en especies cultivadas del Viejo Mundo -incluyendo Hordeum vulgare y Triticum aestivum - frente a diferentes formas de preparación de la comida. Sus investigaciones demostraron, claramente, cómo algunas de ellas produjeron alteraciones únicas e identificables en ciertos morfotipos de granos de almidón y que cada especie vegetal reacciona de forma diferente. En el caso que nos concierne, ofrecen pruebas muy evidentes de que los almidones sometidos a agua a temperatura ambiente (maceración, fermentación) apenas se alteran, aumentando ligeramente su tamaño y expandiéndose el hilum. En cambio, su calentamiento en agua (cocción, hervido, maceración, torrefacción) provoca su hinchazón y la desaparición de algunas variables cualitativas incluyendo el hilum. Si el proceso continúa los granos de almidón se gelatinizan hasta el punto de ser irreconocibles. A medida que estos almidones aumentan su tamaño, los que tienen facetas tienden a redondearse y perderlas. Los almidones de Hordeum vulgare y Triticum aestivum se hinchan en la cocción y pierden el hilum, apareciendo y desapareciendo posteriormente las lamellae. La única característica exclusiva de estas especies, a los diez minutos de cocción, es la aparición de una sombra leve o pliegue, en el centro del grano, previa a la gelatinización.

En definitiva, la gelatinización es un proceso que impide identificar los almidones como tales. Al no poder saber la especie productora no hay datos empíricos demostrables para relacionarlo de modo casi unívoco con la producción de bebidas como la cerveza. Más aún, Henry et al. (2009) demostraron que la fermentación en agua con levaduras (método tradicional de producción de cerveza) apenas modifica los granos de almidón. La única alteración, muy peculiar y exclusiva de los granos de trigo y cebada, es la aparición de áreas como ahuecadas o desaparecidas en los granos, mientras que el borde exterior se conserva intacto. Dichas áreas se interpretan como resultado del ataque de levaduras que se alimentarían del grano de almidón (Samuel 2000) y solo se dieron en un $1-2 \%$ de los granos estudiados (Henry et al. 2009).

Los análisis de almidones realizados en la Península Ibérica relacionan, por ejemplo, la elaboración de cerveza con el contenido de ánforas ibéricas en yacimientos del noreste o identifican la primera cerveza europea por los residuos del contenido de cerámicas campaniformes en el tú-

Trab. Prehist., 69, N. ${ }^{\circ}$ 2, julio-diciembre 2012, pp. 332-348, ISSN: 0082-5638

doi: $10.3989 /$ tp.2012.12095 
mulo de La Sima del valle de Ambrona (JuanTresserras 1998, 2000a, 2000c, 2000d; Rojo et al. 2002-2003)(5). Sin embargo ninguno da cuenta de alteraciones similares a la comentada ni aporta pruebas sobre un aumento métrico de los granos. La presencia de oxalato cálcico junto a almidones de cereales no prueba tal actividad, pues es el biomineral más abundante en todas las plantas superiores, no solo en los cereales, acumulándose en forma de cristales en las células vegetales como producto de los procesos intracelulares (Franceschi y Horner 1980). Tampoco lo es que, en paralelo, se documenten levaduras, pues aunque muchas especies de estos hongos microscópicos estén relacionadas con la fermentación de bebidas alcohólicas, la mayoría vive en la superficie de las plantas o en la capa más superficial del suelo (Kurtzman y Fell 2005).

\section{AGRADECIMIENTOS}

Este trabajo se ha realizado dentro del Programa Consolider de Investigación en Tecnologías para la valoración y conservación del Patrimonio Cultural -TCP-CSD2007-00058, y ha sido financiado también por los proyectos de investigación HAR2008-06477-C03-03/HIST y HAR200809120/HIST (Plan Nacional de I+D+i) y ERC230561 (European Commission). La Universidad de Antioquia apoyó la estancia de Francisco Javier Aceituno en el Centro de Ciencias Humanas y Sociales del CSIC por invitación del grupo de Arqueobiología. Óscar García Vuelta (MicroLab, CCHS, CSIC) nos prestó una inestimable ayuda con el microscopio electrónico y Nicolás Loaiza en el diseño de las figuras.

\section{BIBLIOGRAFÍA}

Aceituno, F. J. y Loaiza, N. 2008: "Rastreando los orígenes de la agricultura en la vertiente oriental del Cauca medio". En C. López y G. Ospina (eds.): Ecología Histórica: interacciones sociedad ambiente a distintas escalas socio temporales. Universidad Tecnológica de Pereira-Universidad del Cauca-SCAR. Pereira: 68-73.

Alonso, N.; Juan-Tresserras, J.; Rodríguez, M. O. y Rovira, N. 2003: "Muestreo arqueobotánico de ya-

(5) Véase n. 1. cimientos al aire libre y en medio seco." En R. Buxó y R. Piqué (dirs.): La recogida de muestras en Arqueobotánica: objetivos y propuestas metodológicas. La gestión de los recursos vegetales y la transformación del paleopaisaje en el Mediterráneo occidental. Museu d'Arqueologia de Catalunya. Barcelona: 29-46.

Aranguren, B.; Becattini, R.; Mariotti Lippi, M. y Revedin, A. 2007: "Grinding flour in Upper Palaeolithic Europe (25.000 years bp)". Antiquity 81: 845-855.

Babot, M. 2003: "Starch grain damage as an indicator of food processing". En D. M. Hart y L. A. Wallis (eds.): Phytolith and Starch Research in the Australian-Pacific-Asian regions: the state of the art. Pandanus Press. Canberra: 69-81.

Balme, J. y Beck, W. E. 2002: "Starch and charcoal: useful measures of activity areas in archaeological rockshelters". Journal of Archaeological Science 29: 157-166.

Barton, H. 2005: "The case for rainforest foragers: the starch record at Niah Cave, Sarawak". Asian Perspectives 44 (1): 56-72.

Barton, H. 2007: "Starch residues on museum artefacts: implications for determining tool use". Journal of Archaeological Science 34: 1752-1762.

Blasco, A.; Edo, M.; Villalba, M. J.; Buxó, R.; JuanTresserras, J. y Saña, M. 1999: "Del cardial al postcardial en la cueva de San Sadurní (Begues, Barcelona). Primeros datos sobre su secuencia estratrigráfica, paleoeconómica y ambiental". En J. Bernabeu y T. Orozco (eds.): II Congrés del Neolític a la Península Ibèrica (València 1999). Saguntum-PLAV Extra-2, Universitat de València. València: 59-67.

Bray, J. R. y Curtis, J. T. 1957: "An ordination of upland forest communities of Southern Wisconsin". Ecological Monographs 27: 325-349.

Buxó, R. 1997. Arqueología de las Plantas. Ed. Crítica. Barcelona.

Buxó, R.; Alonso, N.; Canal, D.; Echave, C. y González, I. 1997: "Archaeobotanical remains of hulled and naked cereals in the Iberian Peninsula". Vegetation, History and Archaeobotany 6: 15-23.

Buxó, R. y Piqué, R. 2008: Arqueobotánica. Los usos de las plantas en la Península Ibérica. Ed. Ariel. Barcelona.

Coil, J.; Korstanje, M. A.; Archer, S. y Hastorf, C. A. 2003: "Laboratory goals and considerations for multiple microfossil extraction in archaeology". Journal of Archaeological Science 30: 991-1008.

Cortella A. R. y Pochettino, M. L. 1994: "Starch grain analysis as a microscopic diagnostic feature in the identification of plant material". Economic Botany 48: 171-181.

Dickau, R. 2005: Resource use, crop dispersal, and the transition to agriculture in prehistoric Panama: evidence from starch grains and macroremains. 
Ph.D. Philadelphia: Doctoral Dissertation, Temple University.

Dickau, R.; Ranere, A. J. y Cooke R. 2007: "Starch grain evidence for the preceramic dispersals of maize and root crops into tropical dry and humid forest of Panama". Proceedings of the National Academy of Sciences of the United States of America 14: 3651-3656.

Esau, K. 1953: Plant anatomy. John Wiley \& Sons Inc. New York.

Franceschi, V. R. y Horner, H. T. 1980: "Calcium oxalate crystals in plants". Botanical Review 46: 361-427.

Fullagar, R.; Field, J.; Denham, T. y Lentfer, C. 2006: "Early and mid Holocene tool-use and processing of taro (Colocasia esculenta), yam (Dioscorea sp.) and other plants at Kuk Swamp in the highlands of Papua New Guinea". Journal of Archaeological Science 33: 595-614.

Fullagar, R.; Furby, J. y Hardy, B. L. 1996: "Residues on stone artefacts: state of a scientific art". Antiquity 70 : 740-745.

Giovannetti, M. A.; Lema, V.; Bartoli, C. y Capparelli A. 2008: "Starch grains characterization of Prosopis chilensis (Mol.) Stuntz and P. flexuosa D.C, and their implications in the analysis of archaeological remains in Andean South America”. Journal of Archaeological Science 35: 2973-2985.

Hardy, K.; Blakney, T.; Copeland. L.; Kirkham. J.; Wrangham, R. y Collins, M. 2009: "Starch granules, dental calculus and new perspectives on ancient diet". Journal of Archaeological Science 36: 248255.

Haslam, M. 2004: "The decomposition of starch grain in soils: implications for archaeological residues analyses". Journal of Archaeological Science 31 (12): 1715-1734.

Henry, D. O.; Hietala, H. J.; Rosen, A. M.; Demidenko, Y. E. y Armagan, T. L. 2004: "Human behavioral organization in the Middle Paleolithic: were Neanderthals different?". American Anthropologist 106: 17-31.

Henry, A. G.; Hudson, H. F. y Piperno, D. R. 2009: "Changes in starch grain morphologies from cooking”. Journal of Archaeological Science 36: 915922.

Henry, A. G. y Piperno, D. 2008: "Using plant microfossils from dental calculus to recover human diet: a case study from Tell al-Raqa'i, Syria”. Journal of Archaeological Science 35: 1943-1950.

Holst, I.; Moreno, J. E. y Piperno, D. R. 2007: “Identification of teosinte, maize and Tripsacum in Mesoamerica by using pollen, starch grains and phitoliths". Proceedings of the National Academy of Sciences of the United States of America 104: 17608-17613.
Hoover, R. 2001: "Composition molecular, structure, and physicochemical properties of tuber and root starches: a review". Carbohydrate Polimers 45 (3): 253-267.

Horrocks, M. 2005: “A combined procedure for recovering phytoliths and starch residues from soils, sedimentary deposist and similar materials". Journal of Archaeological Science 32: 1169-1175.

Horrocks, M.; Irwin, G.; Jones, M. y Sutton, D. 2004: "Starch grains and xylem cells of sweet potato (Ipomea batatas) and bracken (Pteridium esculentum) in archaeological deposits from northen New Zeland". Journal of Archaeological Science 31: 251-258.

ICSN 2011: "The International Code for Starch Nomenclature". http://fossilfarm.org/ICSN/Code.html (consulta 13-I-2012).

Iriarte, J.; Holst, I.; Marozzi, O.; Listopad, C.; Alonso, E.; Rinderknecht, A. y Montaña, J. 2004: "Evidence for cultivar adoption and emerging complexity during the mid-Holocene in the la Plata basin". Nature 432: 614-617.

Juan-Tresserras, J. 1995: "L'aplicació de nous mètodes en la investigació del món de la mort". Citerior, Revista d'Arqueologia i Ciències de l'Antiguitat 1: 203-210.

Juan-Tresserras, J. 1998: "La cerveza prehistórica: investigaciones arqueobotánicas y experimentales". En J. L. Maya, F. Cuesta y J. L. López Pacheco (eds.): Genó: un poblado del Bronce Final en el Bajo Segre (Lleida). Publications Universitat de Barcelona. Barcelona: 239-252.

Juan-Tresserras, J. 2000a: "Estudio de residuos vegetales conservados en recipientes y asociados a material de molienda en yacimientos de la Edad del Hierro del NE de la Península Ibérica". En R. Buxó y E. Pons (dirs.): Els productes alimentaris d'origen vegetal a l'edat del Ferro de l'Europa occidental: de la producció al consum. Museu d'Arqueologia de Catalunya. Girona: 371-377.

Juan-Tresserras, J. 2000b: "Resultats de les anàlisis de residus en material de mòlta". Arqueomediterrània 5: 219-226.

Juan-Tresserras, J. 2000c: "La explotación del territorio peninsular en la Protohistoria: vino, aceite, cereales y textiles. Aportaciones de los análisis arqueobotánicos y de compuestos orgánicos". En T. Ñaco, O. Olesti y A. Prieto (eds.): Análisis paleoambientals $i$ estudi del territorio (Seminario de la COST ACTION G2, Barcelona 1988): 75-85. Barcelona.

Juan-Tresserras, J. 2000d: "La cerveza: un producto de consumo básico entre las comunidades ibéricas del N.E. peninsular". En III Reunió sobre Economia en el Món Ibèric: Ibers. Agricultors, artesans $i$ comerciants (València 1999). Saguntum-PLV Extra-3, Universitat de València. València: 141148. 
Juan-Tresserras, J.; Echave, C. y Albert, R. M. 1996: "El procesado de vegetales y la interpretación funcional del utillaje neolítico de molido y triturado en la Península Ibérica”. En I Congrés del Neolític a la Península Ibérica (Gavà-Bellaterra 1995). Rubricatum 1 (1): 201-206.

Kealhofer, L.; Torrence, B. y Fullagar, R. 1999: “Integrating phytoliths within use-wear/residue studies of stone tools". Journal of Archaeological Science 26: 527-546.

Knutzon, C. A. y Grove, M. J. 1994: "Rapid method for estimation of amylose in maize starches". Cereal Chemistry 71: 469-471.

Kurtzman, C. P. y Fell, J. W. 2005: "Biodiversity and ecophysiology of yeasts". En P. Gábor y C. L. de la Rosa (eds.): The Yeast Handbook. Springer. Berlin: 11-30.

Lamb, J. y Loy, T. H. 2005: "Seeing red: the use of Congo Red dye to identify cooked and damaged starch grains in archaeological residues". Journal of Archaeological Science 32: 1433-1440.

Lentfer, C.; Therin, M. R. y Torrence, R. 2002: "Starch grains and environmental reconstruction: a modern test case from west new Britain, Papua New Guinea". Journal of Archaeological Science 29: 687-698.

Lineback, D. R. y Wongsrikasem, E. 1980: "Gelatinization of starch in baked products". Journal of Food Science 45: 71-74.

Loy, T. 1994: "Methods in the analysis of starch residues on prehistoric stone tools". En J. G. Hather (ed.): Tropical archaeobotany. Applications and new developments. Routledge. London and New York: 86-111.

Loy, T. H.; Spriggs, M. y Wickler, S. 1992: "Direct evidence for human use of plants 28,000 years ago: starch residues on stone artifacts from the northern Salomon Islands". Antiquity 66: 898-912.

McGee, H. 1984: On Food and Cooking: The Science and Lore of the Kitchen. Charles Scribner's Sons. New York.

Mercader, J. 2009: "Mozambican grass seed consumption during the Middle Stone Age". Science 326 (5960): 1680-1683.

Mock, C. y Dick, J. W. 1991: "Response of starch of different wheat classes to ball milling". Cereal Chemistry 68 (4): 409-412.

Pagan, J. R.; Rodríguez, M. A.; Chanlatte, L. A. y Narganes, Y. 2005: "La temprana introducción y uso de algunas plantas domésticas, silvestres y cultivos en las Antillas precolombinas. Una primera revaloración desde la perspectiva del arcaico de Vieques y Puerto Rico". Diálogo Antropológico 10: 7-33.

Pearsall, D. M.; Chadler-Ezell, K. y Zeidler, J. A. 2004: "Maize in ancient Ecuador: results of residue analysis of stone tools from the Real Alto site". Journal of Archaeological Science 31: 423-442.
Perry, L. 2002: "Starch granule size and the domestication of manioc (Manihot esculenta) and sweet potato (Ipomea batatas)". Economic Botany 56 (4): 335-349.

Perry, L. 2004: "Starch analyses reveal the relationship between tool type and function: an example from Orinoco valley of Venezuela". Journal of Archaeological Science 31: 1069-1081.

Perry, L.; Dickau, R.; Zarrillo, S.; Holst, I.; Pearsall, D. M.; Piperno, D. R.; Berman, M. J.; Cooke, R. G.; Rademaker, K.; Ranere, A. J.; Raymond, J. S.; Sandweiss, D. H.; Scaramelli, F.; Tarble, K. y Zeidler, J. A. 2007: "Starch fossils and the domestication and dispersal of chili peppers (Capsicum spp. L.) in the Americas". Science 315: 986-988.

Piperno, D. 2006: Phytoliths: a comprehensive guide for archaeologists and paleoecologists. AltaMira Press. Lanham.

Piperno, D. 2009: "Crop plants with phytoliths (and starch grains) in Central and South America: A review and an update of the evidence". Quaternary International 193: 146-159.

Piperno, D. y Dillehay, T. 2008: "Starch grains on human teeth reveal early broad crop diet in northen Peru". Proceedings of the National Academy of Sciences of the United States of America 105: 19622-19627.

Piperno, D. y Holst, I. 1998: "The presence of starch grains on prehistoric stone tools from de humid Neotropics: indications of early tuber use and agriculture en Panamá". Journal of Archaeological Science 25: 765-776.

Piperno, D. y Pearsall, D. 1998: The origins of agriculture in the lowland Neotropics. Academic Press. San Diego.

Piperno, D.; Ranere, A. J.; Holst, I. y Hansell, P. 2000: "Starch grains reveal early root crop horticulture in the Panamanian tropical forest". Nature 407: 894897.

Piperno, D.; Weiss, E.; Holst, I. y Nadel, D. 2004: "Processing of wild cereals grains in the Upper Paleolithic revealed by starch grains analysis". $\mathrm{Na}$ ture 430: 670-673.

Reichert, E. T. 1913: The differentiation and specificity of starches in relation to genera, species, etc. The Carnegie Institute of Washington. Washington D.C.

Revedin, A.; Aranguren, B.; Becattini, R.; Longo, L.; Marconi, E.; Mariotti Lippi, M.; Skakun, N.; Sinitsyn, A.; Spiridonova, E. y Svoboda, J. 2010: "Thirty thousand-years-old evidence of plant food processing". Proceedings of the National Academy of Sciences of the United States of America 107: 18815-18819.

Rojo, M. A.; García Martínez de Lagrán, I. y Garrido Pena, R. 2002-2003: "La elaboración experimental 
de cerveza prehistórica en el valle de Ambrona". Boletín de Arqueología Experimental 5: 4-9.

Samuel, D. 2000: "Brewing and baking". En P. T. Nicholson y I. Shaw (eds.): Ancient Egyptian materials and technology. Cambridge University Press. Cambridge: 537-576.

Seidemann, J. 1966: Stärke-Atlas. Paul Parey. Berlin.

Swinkels, J. J. M. 1985: "Sources of starch, its chemistry and physic". Starch Conversion Technology. Marcel Dekker. New York: 15-46.

Therin, M.; Torrence, R. y Fullagar, R. 1997: "Australian Museum starch reference collection". Australian Archaeology 44: 52-53.

Thomas, H. D. y Atwell, W. A. 1999: Starches. Practical guides for the food industry. Egan Press. St. Paul, Minnesota.

Tomlinson, K. y Denyer, K. 2003: "Starch synthesis in cereal grains". Advances in Botanical Research 40: 1-47.

Torrence, R. y Barton, H. (eds.) 2006: Ancient starch research. Left Coast Press. Walnut Creek, California.

Torrence, R. y Conway, R. 2006: "Classification using image analysis and multivariate techniques". En R. Torrence y H. Barton (eds.): Ancient Starch Research. Left Coast Press.Walnut Creek, California: 137-142.

Ugent, D.; Pozorski, S. y Pozorski, T. 1982: “Archaeological potato tuber remains from the Casma valley of Peru". Economic Botany 36: 182-192.

Ugent, D.; Pozorski, S. y Pozorski, T. 1984: "New evidence for ancient cultivation of Canna edulis in Peru". Economy Botany 38: 417-432.

Ugent, D.; Pozorski, S. y Pozorski, T. 1986: “Archaeological manioc (Manihot) from coastal of Peru". Economy Botany 40: 78-102.

Vasanthan, T. y Hoover, R. 2009: "Barley starch: production, properties, modification and uses". En J. Be-
Miller y R. Whistler (eds.): Starch: chemistry and technology. Academic Press. New York: 601-625.

Wang, T. L.; Bogracheva, T. Y. y Hedley, C. L. 1997: "Starch: as simple as A, B, C?". Journal of Experimental Botany 28: 481-502.

Ward, J. 1963: "Hierarchical grouping to optimize and objective function". Journal of the American Statistical Association 58: 236-244.

Wilson, J.; Hardy, K.; Allen, R.; Copeland, L.; Wrangham, R. y Collins, M. 2010: "Automated classification of starch granules using supervised pattern recognition of morphological properties". Journal of Archaeological Science 37: 594-604.

Yáñez, C.; Malgosa, A.; Burjachs, F.; Díaz, N.; García, C.; Isidro, A.; Juan, J. y Matamala, J. 2002: "El món funerari al final del V mil·lenni a Andorra: La Tomba de Segudet (Ordino)". Cypsela 14: 175-194.

Yuryev, V. P.; Nemirosvkaya, I. E. y Maslova, T. D. 1995: "Phase state of starch gels at different water content". Carbohydrate Polymers 26 (1): 43-46.

Zapata, L.; Peña Chocarro, L.; Pérez Jordá, G. y Stika, H. P. 2004: "Early Neolithic agriculture in the Iberian Peninsula". Journal of World Prehistory 18 (4): 285-326.

Zapata, L.; Peña Chocarro, L.; Pérez Jordá, G. y Stika, H. P. 2005: "Difusión de la agricultura en la Península Ibérica". En R. Ontañón Peredo, C. GarcíaMoncó y P. Arias Cabal (eds.): III Congreso del Neolítico en la Península Ibérica (Santander 2003): 103-113. Santander.

Zhong-Min, D.; Yan-Ping, Y.; Min, Z.; Wen-Yang, L.; Su-Hui, Y.; Rui-Guo, C. y Zhen-lin, W. 2008: "Distribution of starch granule size in grains of wheat grown under irrigated and rain fed conditions". Acta Agronomica Sinica 34 (5): 795-802.

Zobel, J. F. 1988: "Molecules to granules: a comprehensive starch review". Starch/Stärke 40 (2): 41-50. 